\title{
EFFICACY OF POSTOPERATIVE PARENTERAL TRIMEBUTINE MALEATE IN RECOVERY OF BOWEL FUNCTION FOLLOWING CESAREAN SECTION
}

\author{
By \\ Ahmed S. Kamal, Ismael M. El-Garhy and Mofeed F. Mohammad \\ Obstetrics \& Gynecology Department, Faculty of Medicine, Al-Azhar University (Cairo) \\ Corresponding Author: Ahmed Serag Kamal, \\ Phone: +201100888809, E-mail: ahmedabolo@hotmail.com
}

\begin{abstract}
Background: Postoperative ileus remains a serious clinical problem. It is one of the most important contributors to increased length of hospitalization and consumption of the health care system resources. Attempts have been made to treat several causes simultaneously to quickly restore normal postoperative bowel motility.
\end{abstract}

Objective: The aim of this study was to estimate the effectiveness of postoperative parentally administered Trimebutine maleate inducing intestinal motility after cesarean section.

Patients and Methods: This study included 200 patients who were selected from the outpatient clinic of Obstetrics and Gynecology at Alexandria Armed Forces Hospital. They were classified into two equal groups:

Group (1): Control group underwent traditional management (oral intake of clear fluids and I.V fluids), and Group (2): were infused intravenously by a total dose of $300 \mathrm{mg}$ of Trimebutine maleate per day divided into $100 \mathrm{mg}$ every 8 hours till first passage of flatus. Each group was subdivided into two equal subgroups:

A) GA group underwent cesarean section under general anesthesia,

B) SA group underwent cesarean section under spinal analgesia.

Results: There was a significant difference between GA and SA of the control group in which the SA group decreased in the time in comparison to the GA group in all the outcome measures. There was a significant difference between GA of the cases group and GA of the control group in which the GA of the cases group decreased in the time in comparison to the GA group of the control in all the outcome measures. There was a significant difference between SA of the cases group and SA of the control group in which the SA of the cases group decreased in the time in comparison to the SA group of the control in all the outcome measures. Regarding pain and distension. There was a significant difference between GA and SA of the control group with more cases in the GA group, there was a significant difference between SA of the control and SA of the cases with more cases with the SA of the control.

Conclusion: Trimebutine maleate $\left(\mathrm{GASTREG}^{\circledR}\right)$ routinely administrated to patients after caesarean section speeds recovery of intestinal function postoperatively by stimulating gastrointestinal motility. So GASTREG is an inexpensive, tolerable and helpful measure to postoperative care after caesarean section and other abdominal surgery.

Keywords: Bowel function- cesarean section- parenteral trimebutine- maleate. 


\section{INTRODUCTION}

Cesarean delivery is the most common surgery performed in women worldwide (Abenhaimet al., 2018).

Cesarean section, is the delivery of a baby through a surgical abdominal incision, C-section delivery is performed when a vaginal birth is not possible or is not safe for the mother or child due to a variety of medical and social factors (Farhan, 2013).

The rate of caesarean deliveries is rising worldwide. Both "elective" cesarean deliveries (sometimes defined as unlabored) and "non-elective" cesarean deliveries contribute to this rise specific reference to primary caesarean before onset of labor, CDMR(cesarean delivery on maternal request), medical indications, and mal-presentation as proportions of total caesarean deliveries ;however, the proportions vary by country, study, and time period (Karlström et al., 2013).

Postoperative ileus (POI) is the temporary delay of gastro-intestinal motility after surgery, characterized by abdominal discomfort, anorexia, nausea, vomiting, lack of bowel sounds, and the absence of flatus or stool (Cornwall et al., 2019).

Postoperative ileus (POI) is a common and clinically important problem occurring after surgical procedures that may contribute to significant postoperative morbidity, including delaying enteral nutrition, causing patient discomfort, and prolonged hospitalization. POI may be generally defined as a transient impairment in gastrointestinal (GI) motility in the postoperative setting; however, no standard nomenclature or grading system exists (Lee et al., 2015).

Traditionally, after caesarean delivery a woman is given fluids and calories through intravenous infusion. She is not allowed to take anything by mouth for a period of time that varies from one part of the worldto another and from one hospital to another within the same country ( $\mathrm{Mba}$ et al., 2019).

Postoperative hypo-motility may affect all parts of the GI tract but with differential recovery of normal function (Bielefeldt et al., 2016).

Although some of the mechanisms underlying the abnormal intestinal motility found after surgery have been elucidated, an integrated understanding of the pathophysiology of POI remains elusive (Venara et al., 2016).

There is no single, specific treatment for postoperative ileus. Traditionally, the treatment consisted of routine postoperative nasogastric decompression, intravenous fluids, correction of electrolyte imbalances, and expectant observation. Additional measures may include the use of early oral feeding, early mobilization, and the use of prokinetic agents (Jangjoo et al., 2012).

Trimebutine might be an important drug candidate for OS patients, since it has been used for the treatment of various disorders including IBS, gastritis, and dyspepsia (Hussain et al., 2018).

Trimebutine maleate has been used in treating colon motility disorders as irritable bowel syndrome and postoperative ileus. This suggests that it possesses not only an inhibitory effect, but also a stimulatory effect on bowel 
motility. This agent thus has a unique effect on intestinal motility (Salvioli, 2019).

Trimebutine maleate is a noncompetitive spasmolytic agent. It possesses moderate opiate receptor affinity and has marked antiserotonin activity especially on ' $\mathrm{M}$ ' receptors. Electrophysiological studies have shown that trimebutine maleate exerts a strong spasmolytic papaverine-like activity together with an evident, unusual stimulation of spontaneous activity. It induced a marked regularization of spontaneous activity with an increase in the amplitude of contractions (Hussain et al., 2018).

Trimebutine, which is an enkephalin agonist, has a dual action on both of hyperkinetic and hypokinetic motility disorders, This medication accelerates gastric emptying by inducing premature phase III activity of the migrating motor complex in gut (Yang et al., 2017).

The aim of this study was to estimate the effectiveness of Postoperative parentally administered Trimebutine maleate inducing intestinal motility after caesarean section.

\section{PATIENTS AND METHODS}

This study included 200 patients who selected from the outpatient clinic of Obstetrics and Gynecology at Alexandria Armed Forces Hospital. The duration of the study was from Jan. 2019 till Jan 2020. They were divided into 2 equal groups:

Group (1): (Control group) underwent traditional management (oral intake of clear fluids and I.V fluids). As the type of anesthesia had an effect on intestinal motility, they were further divided into 2 equal groups:

A) GA group underwent cesarean section under general anesthesia, and,

B) SA group underwent cesarean section under spinal analgesia.

Group (2): were infused intravenously by a total dose of $300 \mathrm{mg}$ of Trimebutine maleate per day were divided into $100 \mathrm{mg}$ every 8 hours till first passage of flatus. They further divided into 2 equal groups:

A) GA group underwent cesarean section under general anesthesia, and,

B) SA group underwent cesarean section under spinal analgesia.

\section{Inclusion criteria:}

- Patient aged between 18 and 40 years old.

- Women with term singleton pregnancy (37-40 weeks pregnancy).

\section{Exclusion criteria:}

- Thyroid diseases.

- Inflammatory bowel disease.

- Complaints of chronic constipation (defined as two or less bowel movements per week) before pregnancy.

- Prolonged surgery (more than 50 minutes).

- Obstructed labor as an indication for caesarean section.

- Previous bowel surgery.

- Known hypersensitivity to Trimebutine Maleate is the only contraindication. 
The study was approved by the ethical and research committee of council of Obstetrics and Gynaecology Department, Alexandria University. The study was explained to all enrolled subjects and written consent was taken from each. The intestinal sounds were heard starting 3 hours postoperatively in the four abdominal quadrants then every 3 hours. Data for each patient were collected in a specially designed case record form (CRF).

\section{Demographic data included:}

- Patient's age.

- Gravidity.

- Parity.

- Past medical history.

- Past surgical history.

- Gestational age.

- Bowel habit. Normal bowel habit was defined as one or more bowel motion per day.

The indication of caesarean section was recorded.

\section{Postoperative data recorded including:}

- Administration of NSAIDs and/or opioids.

- Lengths of time until satisfactory intestinal sounds were auscultated.
- First passage of flatus.

- First bowel movement.

Postoperative complications were noted and also postoperative abdominal pain, distension and clinically significant ileus was considered when abdominal distension and non-passage of flatus or bowel movements with or without nausea or vomiting after the $1 \mathrm{st}$ postoperative day.

- Lastly postoperative hospital stay was recorded.

\section{Outcome measures:}

First hearing of intestinal sounds, first passage of flatus, first defecation, hospital stay.

\section{Statistical method:}

The Data was collected and entered into the personal computer. Statistical analysis was done using Statistical Package for Social Sciences (SPSS/version 21) software.

Arthematic mean, standard deviation, for categorized parameters, chai square test was used while for numerical data ttest was used to compare two groups. To find the association between two variables, spearman correlation coefficient test was used the level of significant was 0.05 .

\section{RESULTS}

A. Demographic data and maternal history (Table 1):

1. Age: there were no statistical significant difference between SA of the cases and SA of the control groups
$(\mathrm{P}>0.05)$. There were no significant differences between other groups.

2. Gestational age: There were no statistical significant difference between SA of the cases and SA of the control groups $(P>0.05)$. There were 
no significant differences between other groups.

3. Gravidity: There was a significant difference between GA and SA of the control group ( $\mathrm{P}$ value 0.015). Also there was a significant difference between SA of the control group and the cases group ( $\mathrm{P}$ value 0.001). Regarding parity; there was no significant difference between all groups $(\mathrm{P}>0.05)$.

Table (1): Comparison between the different studied groups according to demographic and maternal data

\begin{tabular}{|c|c|c|c|c|}
\hline Groups & \multicolumn{2}{|c|}{ Control } & \multicolumn{2}{|c|}{ Cases } \\
\hline Data & $\begin{array}{l}\text { General } \\
(\mathbf{n}=\mathbf{5 0})\end{array}$ & $\begin{array}{c}\text { Spinal } \\
(\mathbf{n}=\mathbf{5 0})\end{array}$ & $\begin{array}{c}\text { General } \\
(\mathbf{n}=\mathbf{5 0})\end{array}$ & $\begin{array}{c}\text { Spinal } \\
(\mathbf{n}=\mathbf{5 0})\end{array}$ \\
\hline Age & $27.36 \pm 5.85$ & $26.98 \pm 4.77$ & $26.26 \pm 4.14$ & $25.26 \pm 5.10$ \\
\hline $\mathbf{p}_{1}$ & \multicolumn{2}{|c|}{$>0.05$} & \multicolumn{2}{|c|}{$>0.05$} \\
\hline $\mathbf{p}_{2}$ & & & 0.223 & 0.185 \\
\hline Gestational age & $38.68 \pm 2.17$ & $37.74 \pm 2.88$ & $38.86 \pm 1.93$ & $38.66 \pm 2.15$ \\
\hline $\mathbf{p}_{1}$ & \multicolumn{2}{|c|}{$>0.05$} & \multicolumn{2}{|c|}{$>0.05$} \\
\hline $\mathbf{p}_{2}$ & & & $>0.05$ & $>0.05$ \\
\hline Gravidity & $2.4 \pm 1.088$ & $2.34 \pm 1.117$ & $2.28 \pm 1.161$ & $2.2 \pm 1.03$ \\
\hline $\mathbf{p}_{1}$ & \multicolumn{2}{|c|}{$0.015^{*}$} & \multicolumn{2}{|c|}{$>0.05$} \\
\hline $\mathbf{p}_{2}$ & & & $>0.05$ & $0.001^{*}$ \\
\hline Parity & $1.32 \pm 1.038$ & $1.28 \pm 1.06$ & $1.24 \pm 1.135$ & $1.16 \pm 1.017$ \\
\hline $\mathbf{p}_{1}$ & \multicolumn{2}{|c|}{$>0.05$} & \multicolumn{2}{|c|}{$>0.05$} \\
\hline $\mathbf{p}_{2}$ & & & $>0.05$ & $>0.05$ \\
\hline
\end{tabular}

Data werw presented as Mean \pm S.D

$\mathrm{p}_{1}$ : $\mathrm{p}$ value for Mann Whitney test between general and spinal in cases and control groups $\mathrm{p}_{2}$ :p value for Mann Whitney test between control and cases in general and spinal

There was no statistical significant difference between studied groups according to indication of CS $(\mathrm{P}>0.05-$

Table (2): Comparison between the different studied groups according to indication of CS

\begin{tabular}{|c|c|c|c|c|c|c|c|c|}
\hline \multirow{3}{*}{ Parameters } & \multicolumn{4}{|c|}{ Control } & \multicolumn{4}{|c|}{ Cases } \\
\hline & \multicolumn{2}{|c|}{$\begin{array}{l}\text { General } \\
(n=50)\end{array}$} & \multicolumn{2}{|c|}{$\begin{array}{c}\text { Spinal } \\
(\mathbf{n}=\mathbf{5 0})\end{array}$} & \multicolumn{2}{|c|}{$\begin{array}{l}\text { General } \\
(n=50)\end{array}$} & \multicolumn{2}{|c|}{$\begin{array}{c}\text { Spinal } \\
(n=50)\end{array}$} \\
\hline & 4 & 8.0 & 3 & 6.0 & 2 & 4.0 & 2 & 4.0 \\
\hline $\mathbf{p}_{1}$ & \multicolumn{4}{|c|}{$>0.05$} & \multicolumn{4}{|c|}{$>0.05$} \\
\hline $\mathbf{p}_{2}$ & & & & & \multicolumn{2}{|c|}{$>0.05$} & \multicolumn{2}{|c|}{$>0.05$} \\
\hline $\begin{array}{c}\text { History of } \\
\text { previous surgery }\end{array}$ & 5 & 10.0 & 5 & 10.0 & 4 & 8.0 & 2 & 4.0 \\
\hline $\mathbf{p}_{1}$ & \multicolumn{4}{|c|}{$>0.05$} & \multicolumn{4}{|c|}{$>0.05$} \\
\hline $\mathbf{p}_{2}$ & & & & & \multicolumn{2}{|c|}{$>0.05$} & \multicolumn{2}{|c|}{$>0.05$} \\
\hline \multicolumn{9}{|l|}{$\begin{array}{c}\text { Mode of previous } \\
\text { delivery }\end{array}$} \\
\hline NVD & 17 & 34.0 & 15 & 30.0 & 23 & 46.0 & 13 & 26.0 \\
\hline C.S. & 33 & 66.0 & 35 & 70.0 & 27 & 54.0 & 37 & 74.0 \\
\hline $\mathbf{p}_{1}$ & \multicolumn{4}{|c|}{$>0.05$} & \multicolumn{4}{|c|}{$0.016^{*}$} \\
\hline $\mathbf{p}_{2}$ & & & & & & & & \\
\hline
\end{tabular}

$\mathrm{p}$ : $\mathrm{p}$ value for Chi-square test, MCp: $\mathrm{p}$ value for Monte Carlo test

$\mathrm{p}_{1}: \mathrm{p}$ value between general and spinal in cases and control groups, $\mathrm{p}_{2}: \mathrm{p}$ value between control and cases in general and spinal, *: Statistically significant at $\mathrm{p} \leq 0.05$ 
B. Outcome measures:

1. First hearing of intestinal sounds:

There was a significant difference between GA and SA of the control group $(P<0.05)$. There is a significant difference between GA of the cases group and GA of the control group (P $<0.05)$. There is a significant difference between SA of the cases group and SA of the control group $(\mathrm{P}<0.05)$.

\section{First passage of flatus:}

There was a significant difference between GA and SA of the control group $(P<0.05)$. There is a significant difference between GA of the cases group and GA of the control group ( $\mathrm{P}<$ 0.05).There is a significant difference between SA of the cases group and SA of the control group $(\mathrm{P}<0.05)$.

\section{Time of defecation:}

There was a significant difference between GA and SA of the control group $(\mathrm{P}<0.05)$. There is a significant difference between GA of the cases group and GA of the control group $(\mathrm{P}<$ $0.05)$.There is a significant difference between SA of the cases group and SA of the control group $(\mathrm{P}<0.05)$.

There was a significant difference between GA and SA of the control group $(\mathrm{P}<0.05)$. There is a significant difference between GA of the cases group and GA of the control group $(\mathrm{P}<0.05)$. There is a significant difference between SA of the cases group and SA of the control group $(\mathrm{P}<0.05$ - Table 3).

Table (3): Comparison between the different studied groups according to outcome parameters

\begin{tabular}{|c|c|c|c|c|}
\hline Groups & \multicolumn{2}{|c|}{ Control } & \multicolumn{2}{|c|}{ Cases } \\
\hline Parameters & $\begin{array}{l}\text { General } \\
(\mathbf{n}=50)\end{array}$ & $\begin{array}{c}\text { Spinal } \\
(\mathbf{n}=\mathbf{5 0})\end{array}$ & $\begin{array}{c}\text { General } \\
(\mathbf{n}=50) \\
\end{array}$ & $\begin{array}{c}\text { Spinal } \\
(\mathbf{n}=50)\end{array}$ \\
\hline $\begin{array}{c}\text { Intestinal } \\
\text { sounds (hours) }\end{array}$ & $15.12 \pm 2.84$ & $10.36 \pm 1.84$ & $11.69 \pm 1.92$ & $5.27 \pm 1.81$ \\
\hline $\mathbf{p}_{1}$ & \multicolumn{2}{|c|}{$0.0031^{*}$} & \multicolumn{2}{|c|}{$0.001^{*}$} \\
\hline $\mathbf{p}_{2}$ & & & $0.012^{*}$ & $0.006^{*}$ \\
\hline Flatus (hours) & $24.18 \pm 4.719$ & $18.7 \pm 3.665$ & $20.84 \pm 4.75$ & $9.28 \pm 1.27$ \\
\hline $\mathbf{p}_{1}$ & \multicolumn{2}{|c|}{$0.006^{*}$} & \multicolumn{2}{|c|}{$0.001^{*}$} \\
\hline $\mathbf{p}_{2}$ & & & $0.011^{*}$ & $0.001^{*}$ \\
\hline Defecation & $29.72 \pm 5.24$ & $23.16 \pm 3.638$ & $25.4 \pm 4.309$ & $15.42 \pm 2.295$ \\
\hline $\mathbf{p}_{1}$ & \multicolumn{2}{|c|}{$0.005^{*}$} & \multicolumn{2}{|c|}{$0.001^{*}$} \\
\hline $\mathbf{p}_{2}$ & & & $0.017^{*}$ & $0.003^{*}$ \\
\hline $\begin{array}{c}\text { Hospital stay } \\
\text { (hours) }\end{array}$ & $48.96 \pm 5.356$ & $39.4 \pm 4.940$ & $33.88 \pm 8.153$ & $32.56 \pm 5.876$ \\
\hline $\mathbf{p}_{1}$ & \multicolumn{2}{|c|}{$0.002^{*}$} & \multicolumn{2}{|c|}{$>0.05$} \\
\hline $\mathbf{p}_{2}$ & & & $0.006^{*}$ & $0.022^{*}$ \\
\hline
\end{tabular}

$\mathrm{p}_{1}: \mathrm{p}$ value between general and spinal in cases and control groups

$\mathrm{p}_{2}$ : $\mathrm{p}$ value between control and cases in general and spinal

C. Symptoms of mild ileus (pain and distension- table 4):

\section{Distension:}

There was a significant difference between SA and GA of the control group $(\mathrm{P}<0.05)$. There were 3 cases with abdominal distension in the GA group of the cases versus one case in the SA group but there was no significant difference between SA and GA of the cases group $(\mathrm{P}>0.05)$. There were a significant difference between 
GA of the cases group and GA of the control group $(\mathrm{P}<0.001)$. There were a significant difference between SA of the cases group and SA of the control group $(\mathrm{P}<0.018)$.

2. Pain:

There was a significant difference between SA and GA of the control group $(\mathrm{P}<0.05)$. There was no significant difference between SA and $\mathrm{GA}$ of the cases group $(\mathrm{P}>0.05)$.
There were a significant difference between GA of the cases group and GA of the control group $(\mathrm{P}<0.05)$. There were no significant difference between SA of the cases group and SA of the control group $(\mathrm{P}>0.05)$.

3. Ileus:

Only 2 cases had signs and symptoms of severe ileus. They occurred in GA of the control group.

Table (4): Comparison between the different studied groups according to distension, ileus and pain

\begin{tabular}{|c|c|c|c|c|c|c|c|c|}
\hline \multirow{3}{*}{\begin{tabular}{|c|c|} 
Groups \\
Parameters \\
Distension \\
\end{tabular}} & \multicolumn{4}{|c|}{ Control } & \multicolumn{4}{|c|}{ Cases } \\
\hline & \multicolumn{2}{|c|}{$\begin{array}{c}\text { General } \\
(\mathbf{n}=50)\end{array}$} & \multicolumn{2}{|c|}{$\begin{array}{c}\text { Spinal } \\
(\mathbf{n}=\mathbf{5 0})\end{array}$} & \multicolumn{2}{|c|}{$\begin{array}{c}\text { General } \\
(n=50)\end{array}$} & \multicolumn{2}{|c|}{$\begin{array}{c}\text { Spinal } \\
(\mathbf{n}=\mathbf{5 0})\end{array}$} \\
\hline & 12 & 24.0 & 5 & 10.0 & 3 & 6.0 & 1 & 2.0 \\
\hline $\mathbf{p}_{1}$ & \multicolumn{4}{|c|}{$0.046^{*}$} & \multicolumn{4}{|c|}{$>0.05$} \\
\hline $\mathbf{p}_{2}$ & & & & & \multicolumn{2}{|c|}{$0.013^{*}$} & \multicolumn{2}{|c|}{$0.022 *$} \\
\hline Ileus & 2 & 4.0 & 0 & 0.0 & 0 & 0.0 & 0 & 0.0 \\
\hline Pain & 10 & 20.0 & 5 & 10.0 & 5 & 10.0 & 3 & 6.0 \\
\hline $\mathbf{p}_{1}$ & \multicolumn{4}{|c|}{$0.033^{*}$} & \multicolumn{4}{|c|}{$>0.05$} \\
\hline $\mathbf{p}_{2}$ & & & & & & & & \\
\hline
\end{tabular}

$\mathrm{p}_{1}: \mathrm{p}$ value between general and spinal in cases and control groups $\mathrm{p}_{2}: \mathrm{p}$ value between control and cases in general and spinal

D. Positive correlations:

1. Correlation between age and first passage of flatus:

There were a significant positive correlation between age and the first passage of flatus in both the GA and SA groups of the control group. Similar results were not observed in the cases group.
2. Correlation between the number of cesarean sections and first passage of flatus:

There were a significant positive significant correlation between flatus with age and number of caesarean sections.

Table (5): Correlation between flatus with age and the number of cesarean sections

\begin{tabular}{|c|c|c|c|c|c|}
\hline & & \multicolumn{2}{|c|}{ Control } & \multicolumn{2}{c|}{ Cases } \\
\hline & & General & Spinal & General & Spinal \\
\hline \multirow{2}{*}{ Age } & $\mathbf{r}_{\mathbf{s}}$ & $0.685^{*}$ & $0.526^{*}$ & -0.1381 & 0.09 \\
\cline { 2 - 6 } & $\mathbf{p}$ & 0.0013 & 0.002 & $>0.05$ & $>0.05$ \\
\hline \multirow{2}{*}{ Number of cs } & $\mathbf{r}_{\mathrm{y}}$ & $0.655^{*}$ & $0.568^{*}$ & -0.101 & -0.231 \\
\cline { 2 - 6 } & $\mathbf{p}$ & 0.0012 & 0.0019 & $>0.05$ & $>0.05$ \\
\hline
\end{tabular}



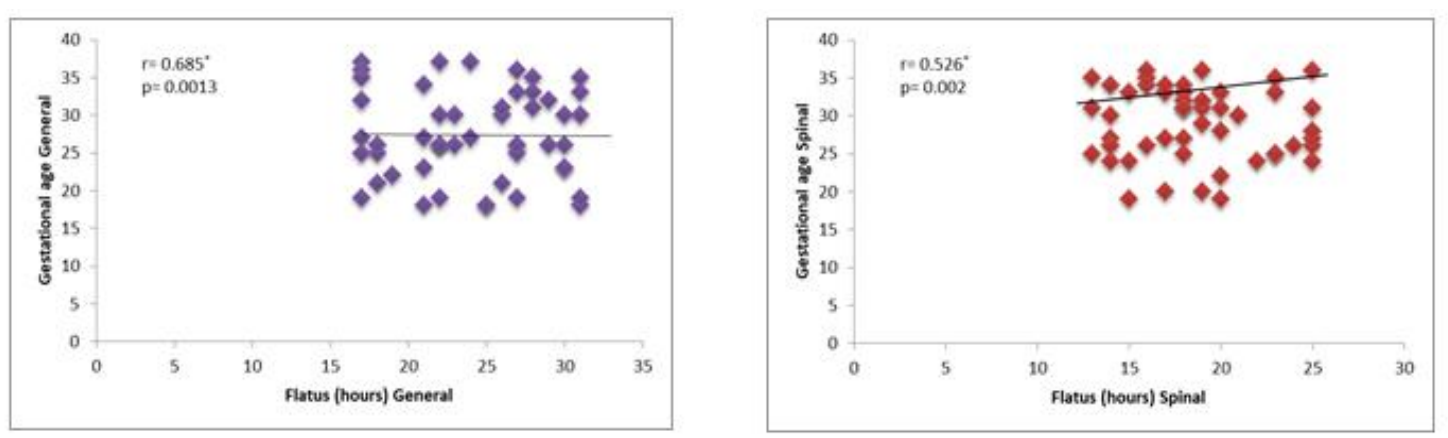

Figure (1): Correlation between flatus with age
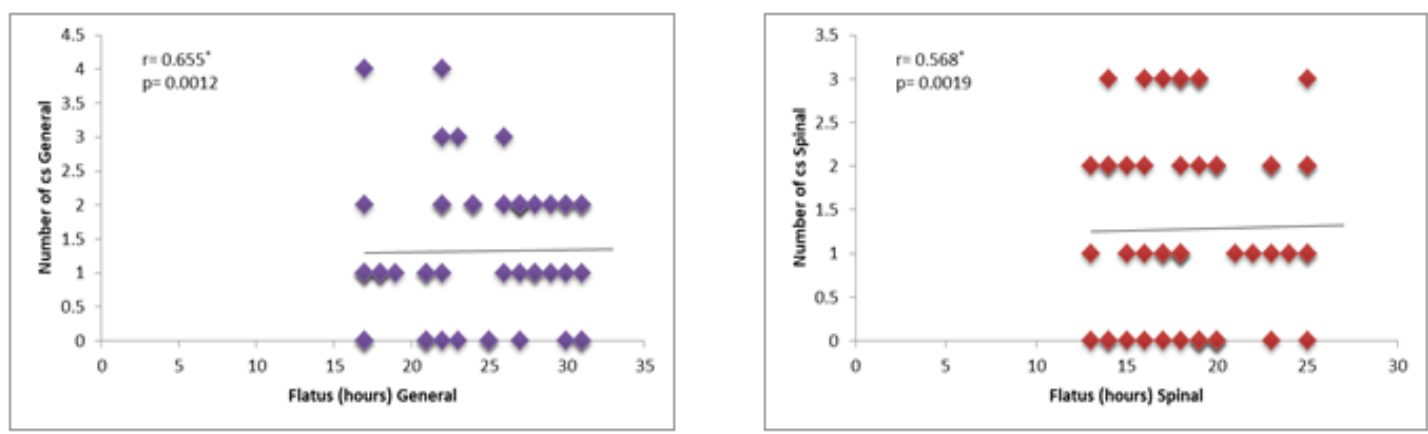

Figure (2): Correlation between flatus with previous CS delivery

\section{DISCUSSION}

To the best of our knowledge; the present study was the first one which evaluates the effect of trimebutine (GASTREG) on resumption of intestinal function after cesarean section.

Regarding the GA group of the control group, the outcome measures were $15.12 \pm 2.84, \quad 24.18 \pm 4.719, \quad 29.72 \pm 5.24$, $48.96 \pm 5.356$ for the first return of intestinal sounds, first passage of flatus, first defecation and hospital stay respectively.

Wen et al. (2017) evaluated the effect of gum chewing on the return of intestinal motility after caesarean section under general anesthesia. The outcome measures for the control group were 11.2 \pm 1.0 , $19.4 \pm 5.4,37.4 \pm 13.9$ for first return of intestinal sounds, first flatus, and first defecation respectively. The difference between this previous study and our study may be attributed to the little number of cases in the previous study.

Regarding the SA group of the control group, all the outcome measures significantly decreased in the SA group compared to the GA group with a percent of change of $30.0 \%, 22.0 \%, 21.0 \%, 18.0 \%$ respectively less with the $\mathrm{SA}$ group denoting faster return of intestinal function in patients under spinal analgesia than patients under general anesthesia.

The available data on postoperative intestinal function with spinal analgesia involve small studies, covering a wide range of surgical procedures. These studies have been the subject of metaanalyses in the last decade. These metaanalyses showed accelerated recovery of intestinal function in all cumulated studies and subsets of studies in colorectal surgeries. Spinal analgesia resulted in a faster resolution of postoperative ileus after major non-intestinal surgery. 
In a study which evaluated intestinal motility under spinal analgesia for patients undergoing cesarean section, the time interval to bowel motion was $25.3 \pm 5.4$ hrs. The faster resolution of postoperative ileus after major open surgery had been attributed to reduced opioid consumption and sympathetic block (American Society of Anesthesiologists, 2016).

In the last decade, systemic lidocaine has been studied and shown to improve postoperative intestinal motility and hospital stay after surgery.

Two small studies compared systemic lidocaine with spinal analgesia. After colonic surgery; pain control and intestinal recovery were more effective with spinal analgesia than with systemic lidocaine (American Society of Anesthesiologists, 2016).

The effects of spinal sympathicolysis on gastrointestinal motility, motility improved significantly within the first 12 hours. $46 \%$ of patients defecated within $12 \mathrm{~h}$, and $35 \%$ within 24 hours. Four of the remaining patients, defecated during the second day after the beginning of the sympathicolysis. One patient remained without defecation within 48 hours and received a second treatment with success.

Regarding the GA group of the cases, all the outcome measures decreased in comparison with the GA group of the control. Regarding the SA group of the cases, all the outcome measures decreased in comparison with the SA group of the control. The first return of intestinal sounds was with a percent change of $49.0 \%$ less with the SA group of the cases. The first passage of flatus was with a percent change of $45.0 \%$ less with the SA group of the cases. The first defecation was with a percent change of $28.0 \%$ less with the SA group of the cases. The hospital stay was with a percent change of $24.1 \%$ less with the SA group of the cases.

Trimebutine maleate has been extensively used in various clinical trials involving subjects with irritable bowel syndrome. In three of these studies, the efficacy of trimebutine maleate was superior to placebo; the improvement was statistically significant. Also, analysis of single stool transit (one study) time showed a significant acceleration of transit in patients receiving trimebutine maleate, the median stool transit time being reduced from 52 to 25 hours (Hussain et al., 2018).

In a double-blind, cross-over study conducted by tablets, trimebutine maleate $200 \mathrm{mg}$ daily was administered orally for one month to 24 patients suffering from chronic idiopathic constipation. Results indicated that colonic transit time was significantly reduced with trimebutine maleate in patients with "delayed" transit time, while it did not change with placebo (Tablets, 2011).

In the controlled studies, trimebutine maleate was administered at doses of 100 to $400 \mathrm{mg}$ by intravenous or intramuscular routes. Overall results indicated that trimebutine maleate was well tolerated by patients. The time interval to passage of first intestinal gas was shorter in trimebutine maleate treated patients as compared to placebo group. Also, the resumption of intestinal motility was significantly faster in comparison with placebo. In addition, patients in trimebutine maleate group felt less abdominal discomfort than those in placebo group (Tablets, 2011). 
In the 11 open studies, resumption of gases appeared within 48 hours in $66.4 \%$ of cases while in $85.4 \%$ it appeared within 72 hours. As in the controlled studies, trimebutine maleate helped in improving the postoperative conditions of patients as their abdominal and colonic discomfort, abdominal pain and nausea decreased (Tablets, 2011).

Results indicated that trimebutine maleate had an intense contractile activity on the intestine of the 29 patients treated with the drug compared to 13 patients who did not receive it. Clinically, the study showed that the duration of paralytic ileus was notably shorter in patient treated with trimebutine maleate than in the control group. The passage of the first postoperative gas was reduced by an average of $23 \%$ by trimebutine maleate. It was also noted that trimebutine maleate attenuated the symptoms associated with ileus, namely nausea, vomiting, distention and abdominal pain (Tablets, 2011).

\section{CONCLUSION}

Trimebutine maleate (GASTREG ®) routinely administrated to patients after cesarean section speeded recovery of intestinal function postoperatively by stimulating gastrointestinal motility. So, GASTREG is an inexpensive, tolerable and helpful measure to postoperative care after cesarean section and other abdominal surgery. Early resumption of gastrointestinal function is associated with shorter duration of intravenous fluids, decreased time to first passage of flatus, first defecation and more rapid return to regular diet. So, it decreases the hospital cost. Also, earlier discharge allowed patient to return home sooner to her family and an environment that is for less disruptive to her and her baby. So, trimebutine maleate $\left(\right.$ GASTREG $\left.^{\circledR}\right)$ should be added as an adjuvant treatment in postoperative care.

Regarding the type of anesthesia, spinal analgesia was associated with a better postoperative recovery, earlier passage of flatus and earlier defecation compared to general anesthesia.

\section{RECOMMENDATIONS}

It is recommended to administer trimebutine maleate $\left(\right.$ GASTREG $\left.^{\circledR}\right)$ routinely as an inexpensive, tolerable drug to speed recovery of gastrointestinal function postoperatively after caesarean section as total dose of $300 \mathrm{mg}$ divided into $100 \mathrm{mg}$ ( 2 ampoules) every 8 hours till first passage of flatus then continue with the tablet form at home.

It is recommended to offer spinal analgesia to patients undergoing caesarean section as it is associated with a better postoperative and gastrointestinal function recovery.

\section{REFERENCES}

1. Abenhaim HA., Tulandi T., Wilchesky M., Platt R., Spence AR., Czuzoj-Shulman N and Suissa S. (2018): Effect of Cesarean Delivery on Long-term Risk of Small Bowel Obstruction. Obstet Gynecol. 131(2):354-359.

2. American Society of Anesthesiologists (2016): Committee on Standards and Practice Parameters Practice Guidelines for Obstetric Anesthesia: An Updated Report by the American Society of Anesthesiologists Task Force on Obstetric Anesthesia and the Society for Obstetric Anesthesia and Perinatology; Obstetric Anesthesia Digest., 36(4): 176-180.

3. Bielefeldt K., Tuteja A. and Nusrat, S. (2016): Disorders of gastrointestinal hypomotility. F1000Research, 5, F1000 Faculty Rev-1897. 
4. Cornwall HL., Edwards BA., Curran JF and Boyce S. (2019): Coffee to go? The effect of coffee on resolution of ileus following abdominal surgery: A systematic review and meta-analysis of randomised controlled trials. ClinNutr. Clinical Nutrition (Edinburgh, Scotland), 39(5):1385-1394.

5. Farhan AS. (2013): A Comparative Study between Two Different Techniques For Caesarean Delivery In SayedGalal Hospital. AAMJ, 11(1): 250-269

6. Hussain Z., Jung DH., Lee, YJ and Park H. (2018): The Effect of Trimebutine on the Overlap Syndrome Model of Guinea Pigs. Journal of Neurogastroenterology and Motility, 24(4): 669-675.

7. Jangjoo A., Mohammadipoor F., Fazel A., Bahar, M., Aliakbarian M. and Nooghabi J. (2012): The role of nasogastric intubation on postoperative gastrointestinal function in patients with obstructive jaundice.The Indian Journal of Surgery, 74(5): 376-380.

8. Karlström A., Lindgren H. and Hildingsson IM. (2013): Maternal and Infant Outcome after Caesarean Section without Recorded Medical Indication: Findings from a Swedish CaseControl Study. BJOG An International Journal of Obstetrics \&Gynaecology, 120(4): 132-136.

9. Lee TH., Lee JS., Hong SJ, Jang JY., Jeon SR., Byun DW., Park WY., Kim SI., Choi HS., Lee JC and Lee J. S. (2015): Risk factors for postoperative ileus following orthopedic surgery: the role of chronic constipation. Journal of Neurogastroenterology and Motility, 21(1): 121-125.

10. Salvioli B. (2019): Trimebutine: a state-of-theart review. Minerva GastroenterolDietol., 65(3):229-238.

11. Tablets TM. (2011): Product monograph. Modulon ${ }^{\circledR} \quad$ (trimebutine maleate), Lower Gastrointestinal Tract Motility Regulator. AptalisPharma Canada, Inc.

12. Venara A., NeunlistM., SlimK., BarbieuxJ., Colas.PA., HamyA and MeuretteG. (2016): Postoperative ileus: Pathophysiology, incidence, and prevention. J Visc Surg., 153(6): 439-446.

13. Wen Z., Shen M., Wu C. (2017): Chewing gum for intestinal function recovery after caesarean section: a systematic review and meta-analysis. BMC Pregnancy Childbirth 17, 105-109.

14. Yang YJ., Bang CS., Baik GH., Park TY., Shin SP., Suk KT and Kim DJ. (2017): Prokinetics for the treatment of functional dyspepsia: Bayesian network meta-analysis. BMC Gastroenterology. 17(83): 56-59. 


\section{تأثير حقن عقار الترايميبيوتين ماليبت على حركة الأمعاء بعد الولادة القيصرية مئية}

أحمد سراج الدين كمال، إسماعيل محمد الجارحي، مفيد فوزي محمد

قسم النساء والتوليد، كلية الطب، جامعة الأزهر

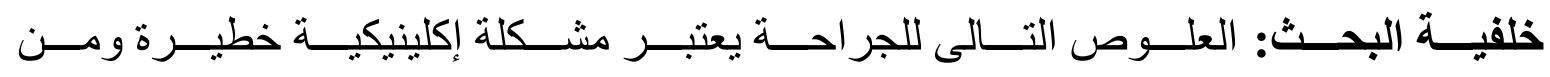

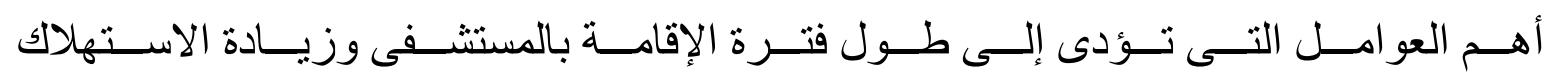
للموارد الصحية.

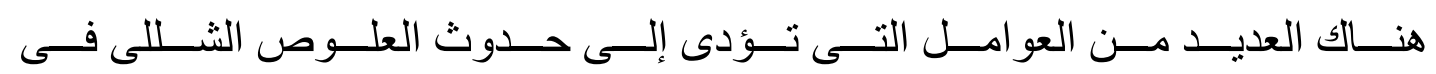

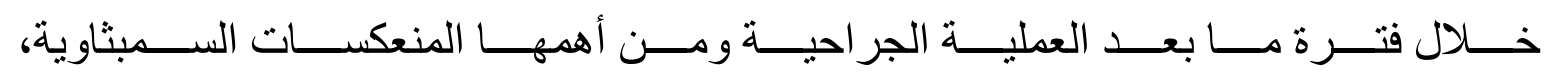
الالتهابات، المو اد المخدرة التى تؤدى إلى تعطل حركة الأمعاء.

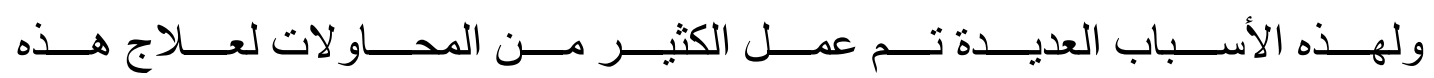
الأسباب لاسترجاع حركة الأمعاء الطبيعية.

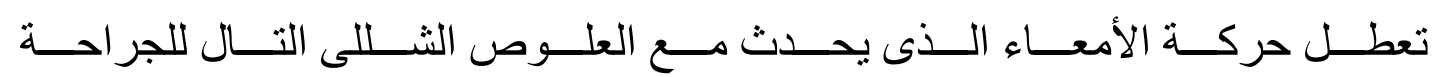

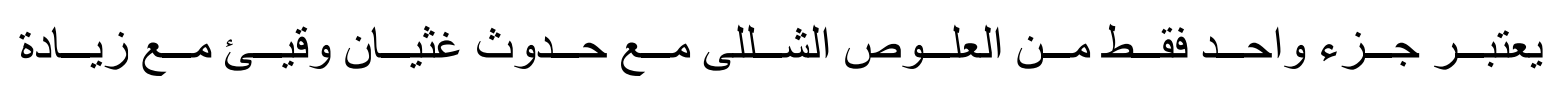
الآلام بعد العملية، التأخير فى الطعام مع طول مدة الإقامة فى المستشفى.

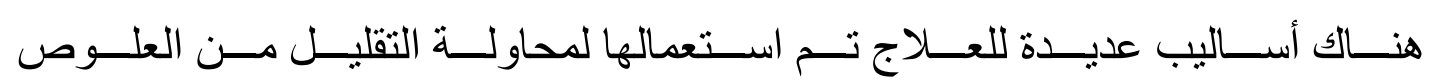
الثللى التال للجر احة.

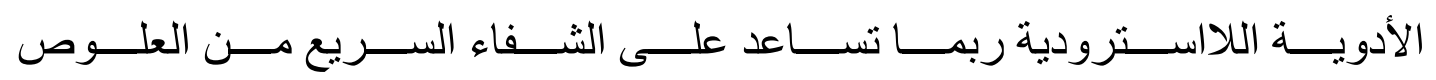

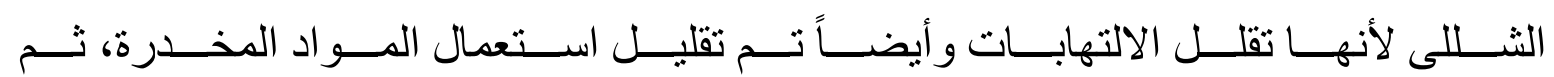
استعمال الأدوية المنشطة للأمعاء.

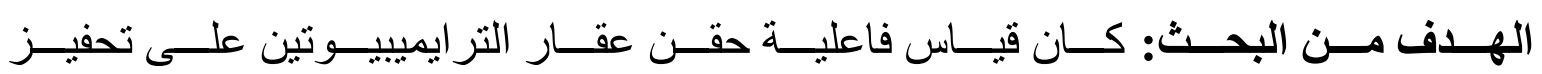
حركة الأمعاء بعد الو لادة القيصرية. 


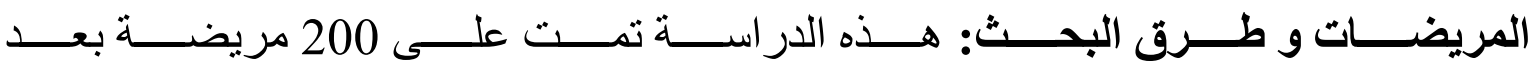
العمليات القيصرية وتم تقسيمهن إلى:

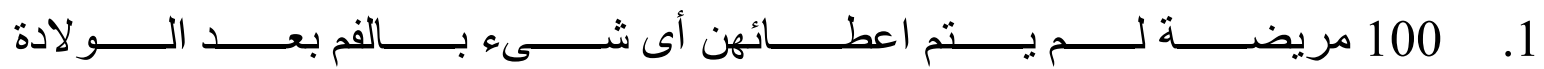
القيصرية.وهؤلاء تم تقسيمهم الى:

أـ - 50 مريضة تم عمل قيصرية لهن تحت مخدر عام.

ب- 50 مريضة تم عمل قيصرية لهن بمخدر نصفى.

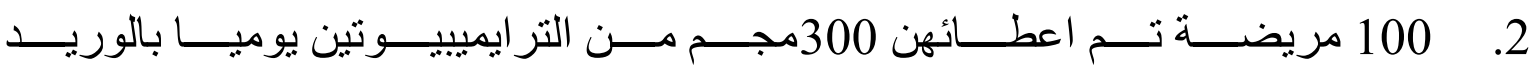

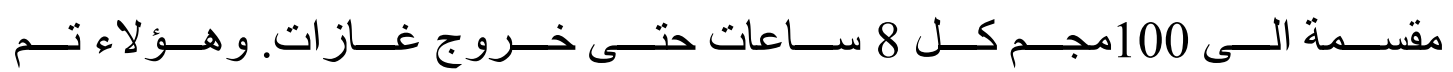

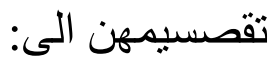

أـ - 50 مريضة تم عمل قيصرية لهن تحت مخدر عام. ب- 50 مريضة تم عمل قيصرية لهن بمخدر نصفى.

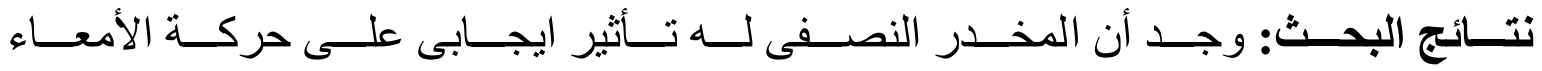

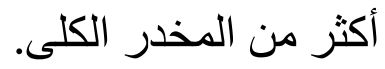

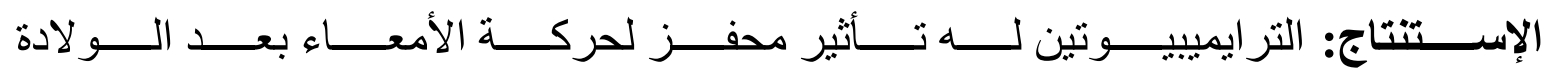

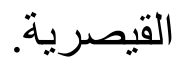

